\title{
THE HEAT OF VAPORIZATION OF OXYGEN, NITROGEN AND AIR.
}

By J. S. Shrarer.

I $\mathrm{N}$ a recent determination of the heat of vaporization of air ${ }^{1}$ it was observed that the results varied in a fairly definite way with the change of composition of the liquid. It seemed desirable to determine this constant for each of the constituents in order that a comparison could be made of the heat required to vaporize corresponding amounts of oxygen and nitrogen when separate and when mixed as liquid air.

The apparatus used was described in the former paper and the only changes found desirable were to use manganin wire instead of german silver, as the latter becomes very brittle after several immersions in liquid air, and to use a chronograph to record the times when meter readings were taken. The gases were liquefied by using liquid air as a cooling agent and subjecting the cold gas to considerable pressure. The apparatus used is shown in Fig. I. Compressed gas from the cylinder $C$ passed through an iron tube filled with caustic potash and then through a coil of fine copper tubing into a receptacle $R$. A gauge $G$ indicates the drop

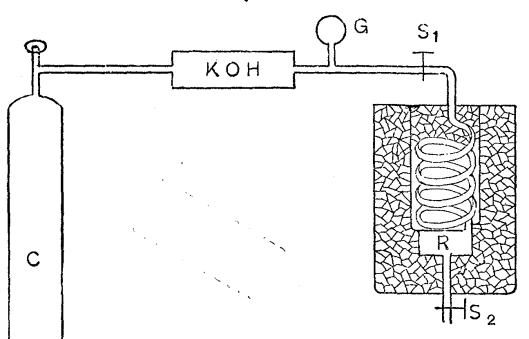

Fig. 1. in pressure due to condensation, and when the pressure became constant the coil and receptacle were known to be filled with liquid. On closing stopcock $S_{1}$ and opening $S_{2}$ the liquid could be removed without wasting gas from the cylinder. This operation was repeated 
until the pressure in $C$ became so low that further liquefaction was impossible. Oxygen liquefied very rapidly at pressures between 40 and 200 pounds per square inch but higher pressures are needed for nitrogen. A more economical method would be to use much greater pressures with small cylinders which could be entirely immersed in liquid air.

The oxygen was secured by electrolysis of water and after passing through caustic potash was found by analysis to be 98.8 to 99.9 per cent. pure. Atmospheric nitrogen was separated from oxygen by drawing air through iron tubes filled with copper turnings and heated above a red heat. The tubes used were two inches in diameter and about twenty inches long joined so as to make a rectangular coil giving approximately seventeen feet of copper packing. About 200 liters of nitrogen per hour was developed containing less than .5 per cent. oxygen. After filling the receiving reservoir, coal gas was passed through the hot coil, reducing the copper oxide, thus keeping up the activity of the copper.

The rate of vaporization was very constant when using the pure liquids even when considerable heat was developed by the coil, but when using liquid air there was a tendency to superheating and the meter readings were less regular. It is probable that the gas given off somewhat explosively when the current was used contained a larger quantity of nitrogen than that given off just before or just after this occurrence. Both of these facts tend to make it more difficult to get concordant results with liquid air than with the pure liquids.

A sample set of data for each gas may be of some interest.

\begin{tabular}{|c|c|c|}
\hline \multicolumn{3}{|l|}{ Liquid Oxygen. December 19, rgo2. } \\
\hline Duration of run, & 828 & sec. \\
\hline Loss rate (no current) I liter in & 76 & sec. \\
\hline Total amount of gas registered by meter, & 45 & liters. \\
\hline Net amount due to energy from current, & 34.1 & liters. \\
\hline Mean temperature of gas at meter, & $16.3^{\circ}$ & C. \\
\hline Mean value of current, & 1.22 & amperes. \\
\hline Mean potential difference at terminals of heating coil, & 10.97 & volts. \\
\hline Barometric pressure, & 74 & $\mathrm{~cm} . \mathrm{Hg}$. \\
\hline Density of oxygen at $0^{\circ}-76 \mathrm{~cm}$. $\mathrm{Hg}$, & 1.429 & gm. per liter. \\
\hline Variation of voltage during run, & .02 & volt. \\
\hline Heat of vaporization, & 59.5 & (minimum). \\
\hline
\end{tabular}




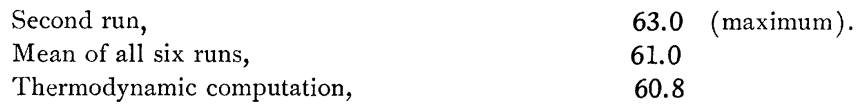

The variation in the determinations of the temperature coefficient of vapor pressure is from 70 to 80 , a much higher percentage than in the results of the heat of vaporization.

\begin{tabular}{|c|c|c|}
\hline Nitrogen. March 27, I903. & & \\
\hline Duration of run, & 309.6 & sec. \\
\hline Time to lose I liter (no current), & 135.0 & sec. \\
\hline Total register by meter, & 30.0 & liters. \\
\hline Net vaporization due to current, & 27.71 & liters. \\
\hline Average current, & 1.54 & amperes. \\
\hline Average voltage, & 13.61 & volts \\
\hline Average temperature, & $21.5^{\circ}$ & C. \\
\hline Barometer, & 73.7 & $\mathrm{~cm} . \mathrm{Hg}$. \\
\hline Density of nitrogen (grams per liter), & 1.427 & \\
\hline Heat of vaporization, & 49.73 & calories per gram. \\
\hline
\end{tabular}

Another run required 308.2 seconds to vaporize 30 liters as against 309.6 above. The mean value found from a series of similar observations was 49.83 ; the greatest variation from the mean was.i I. The result agrees very well with that computed from the vapor tension, which gives 49.25 .

The composition of the vapor given off was found by pyrogallol absorption. The following convenient method was used to determine the corresponding liquid composition. The analysis of the liquid and vapor phases have been given by Baly and by Linde who allowed small portions of the liquid to vaporize completely in order to determine the liquid phase. If however readings of the meter are taken at small intervals from the start until all the liquid is vaporized and the vapor given off at each meter reading is analyzed a curve may be plotted using percentages of oxygen as ordinates and total amount of gas developed as abscissæ. The area of this curve gives the total oxygen content of the original liquid. The amount of oxygen in the liquid at any point is the area between the curve, the $x$ axis, the ordinate at that point and the final ordinate. The composition of the liquid may thus be determined without in any way disturbing the process of vaporization. The results are given in the curves (Fig. 2). A comparison between the observed results and those computed assuming that the heat used for each component is 
472 J. S. SHEARER. [VOL. XVII.

\begin{tabular}{c|c|c}
\hline Per Cent. 0. & $\begin{array}{c}\text { Heat of Vaporization } \\
\text { Observed. }\end{array}$ & $\begin{array}{c}\text { Heat of Vaporization } \\
\text { Computed. }\end{array}$ \\
\hline 48 & 50.6 & 54 \\
66.5 & 57.9 & 56.8 \\
90 & 59 & 59.8 \\
\hline
\end{tabular}

TABLE I.

Curves I and II.

\begin{tabular}{l|c|c||c|c|c}
\hline $\begin{array}{c}\text { Per Cent. } \\
\text { O Vapor. }\end{array}$ & $\begin{array}{c}\text { Liters } \\
\text { Evaporated. }\end{array}$ & $\begin{array}{c}\text { Per Cent. } \\
\text { O Liquid } \\
\text { Computed. }\end{array}$ & $\begin{array}{c}\text { Per Cent. } \\
\text { O Vapor. }\end{array}$ & $\begin{array}{c}\text { Liters } \\
\text { Evaporated. }\end{array}$ & $\begin{array}{c}\text { Per Cent. } \\
\text { O Liquid } \\
\text { Computed. }\end{array}$ \\
\cline { 1 - 2 } 16.8 & 0 & 44.3 & 79 & 472 & 91.8 \\
18.9 & 100 & 50 & 91.4 & 520 & 96.3 \\
25 & 216 & 59 & 95.5 & 543 & 97.8 \\
31.5 & 278 & 65.3 & 98 & 560.5 & 98.9 \\
44.5 & 347 & 73.8 & & 580.1 (final). & \\
61 & 419 & 83.5 & & & \\
\hline
\end{tabular}

TABLE II.

Curves III and $I V$.

\begin{tabular}{c|c|c|c}
\hline Per Cent. O Vapor. & Per Cent. O Liquid. & Per Cent. Total Gas. & Abs. T. [Baly]. \\
\cline { 2 - 4 } 16.8 & 44.3 & 0 & 80.7 \\
17.5 & 47.3 & 10 & 81.0 \\
19.5 & 51.0 & 20 & 81.3 \\
22.2 & 55.1 & 30 & 81.7 \\
26.1 & 61.5 & 40 & 82.4 \\
33.3 & 66.6 & 50 & 83.5 \\
44.6 & 73.8 & 60 & 85.1 \\
58.0 & 81.5 & 70 & 86.7 \\
77.0 & 91.0 & 80 & 88.8 \\
91.9 & 96.2 & 90 & 90.2 \\
& & 100 & 90.6 \\
\hline
\end{tabular}

TABLE III. ${ }^{1}$

Curve IV.

\begin{tabular}{c|c||c|c}
\hline T. Ab. T.C. & Per Cent. O Vapor. & T. Ab. T.C. & Per Cent. O Vapor. \\
\hline $80-193$ & 12 & $86-187$ & 52.3 \\
$81-192$ & 17.6 & $87-186$ & 60.3 \\
$82-191$ & 24 & $88-185$ & 69.5 \\
$83-190$ & 30 & $89-184$ & 79.2 \\
$84-189$ & 36.8 & $90-183$ & 89.6 \\
$85-188$ & 44.4 & $91-182$ & \\
\hline
\end{tabular}

Boiling point of $\mathrm{O} 90.6^{\circ} \mathrm{A} .-182.4^{\circ} \mathrm{C}$.

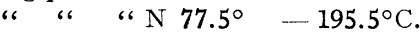

1 Baly, Phil. Mag., 49, 217. Also Traver's Study of Gases. 


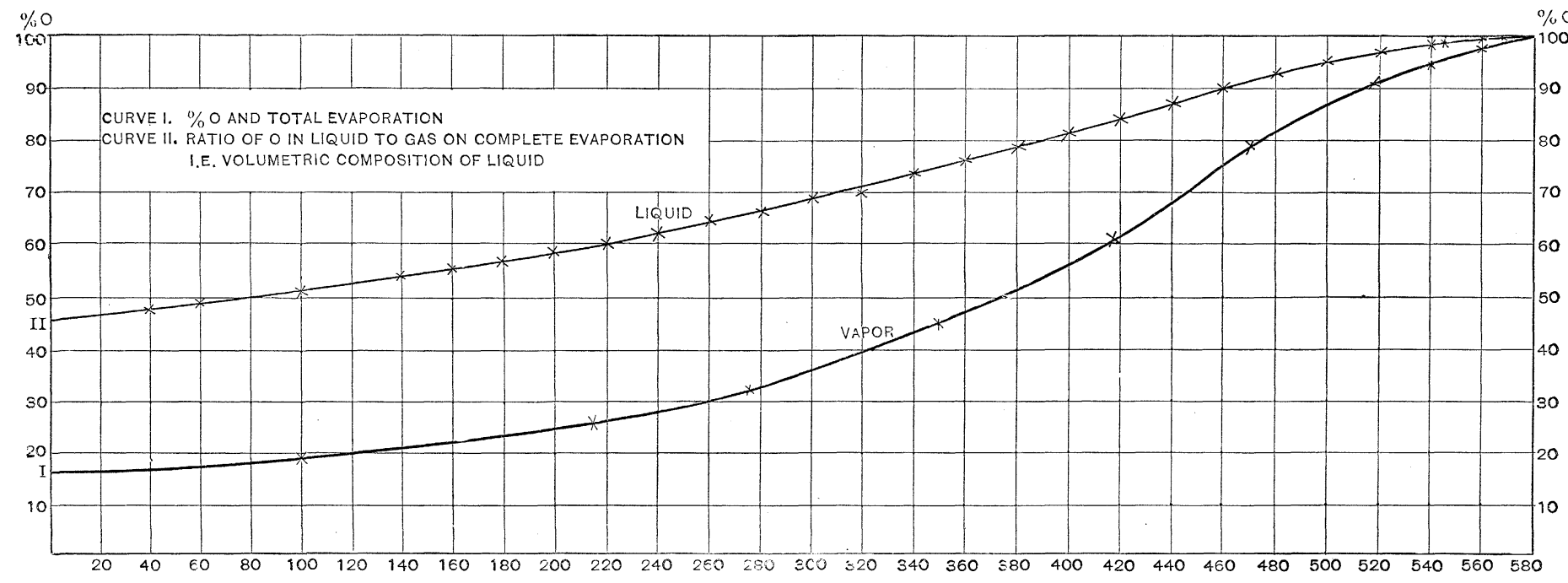

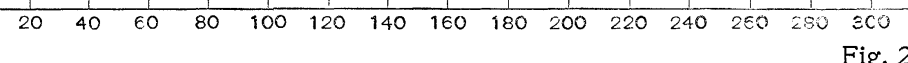




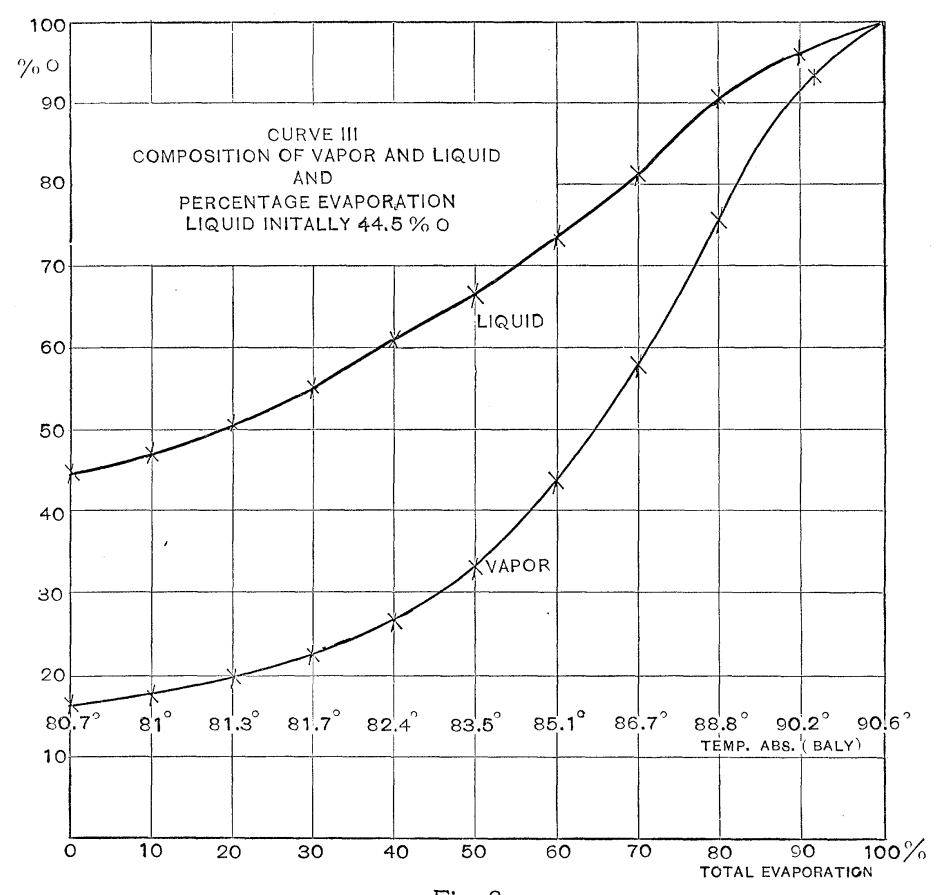

Fig. 3.

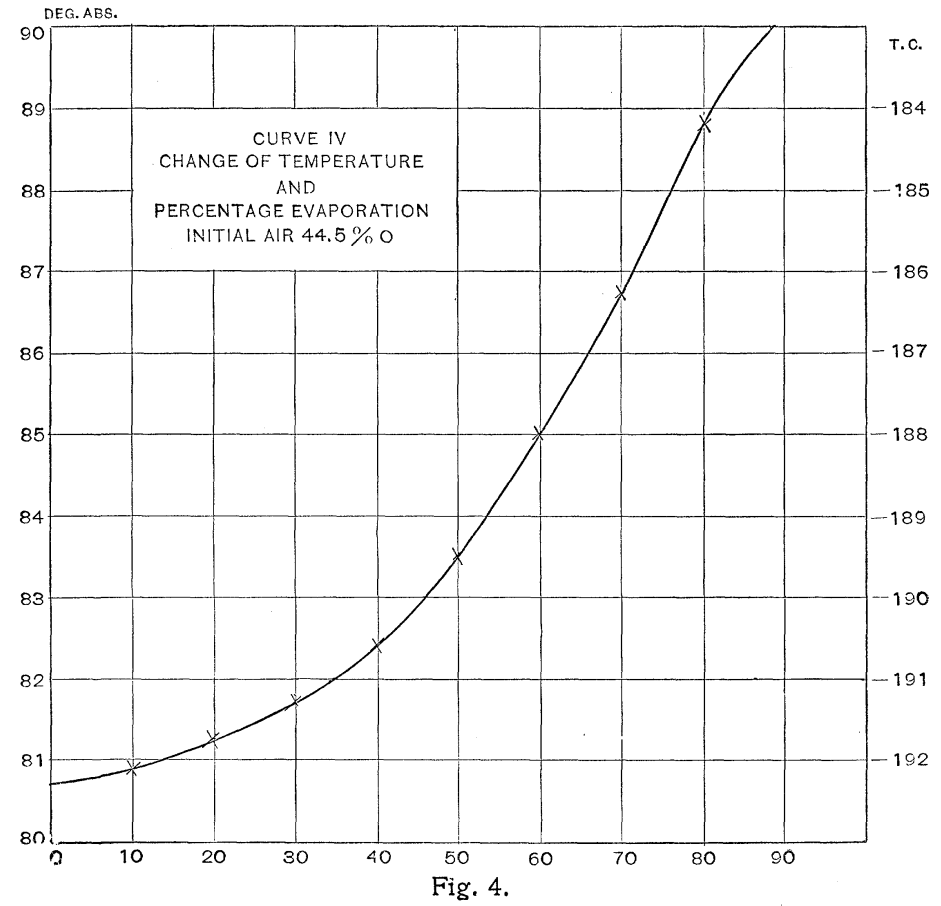


the same as would be required to vaporize the same amount from the pure liquids is shown below. The agreement is not very exact but is as close as could be expected owing to the difficulties noted above.

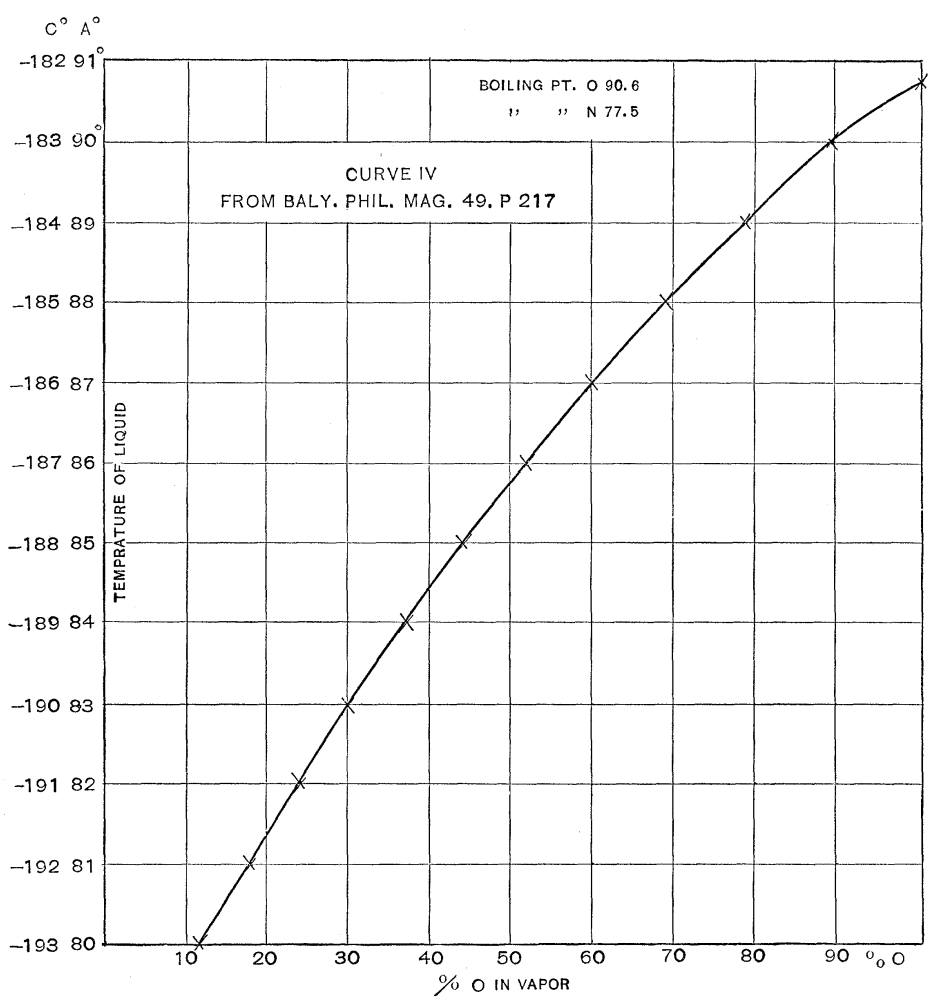

Fig. 5.

For convenience in reference curves are added showing the variation in temperature with percentage of entire liquid evaporated. The values of the temperatures for various compositions of the vapor phase were taken from Baly. ${ }^{1}$

Physical Laboratory, Cornell University, August, 1903.

1 Phil. Mag. (49), p. 417, 1900. 